\title{
Processing of Rolling Technologies for Alloy 718
}

\author{
Michael Walter ${ }^{1}$, Arnold Tatschl $^{1}$ \\ ${ }^{1}$ Bohler Edelstahl GmbH
}

Keywords: Thermomechanical Processing, Rolling, Microstructure Evaluation

\begin{abstract}
The need of thermomechanical processing of Alloy 718 for tighter properties is well known and published mainly for forged products. Less information are published for rolled products, while the today's requirements for increased productivity lead to the replacement from forging trough rolling steps, wherever it is possible. At Böhler-Edelstahl $\mathrm{GmbH}$ several rolling technologies for alloy718 products were developed.

Cogging of 20inch ingots, two-heat-rolling from ingot to bar for AMS 5662/3 and 3 heat rolling to flat $2 \times 0.5$ inch for extended properties show the range of different rolling processes following the TMP demands of alloy 718. The aim was to establish the needed combination of temperature- and deformation windows in the relevant steps over the cross section of the real format. The evaluated aggregates varied from reverse roughing to continuous precision mills with flat and grooved rolls. The main challenge was the transmission of the thermomechanical demands to the technical possibilities of the aggregates. The method was a combination of simplified calculation model based on 2D FDM and systematic trials with an intense metallurgical evaluation. While the behavior of alloy 718 in single or several step deformation is predictable with FEM and attached micro structural models, in multi pass rolling a save prediction is not possible. The main reason is that the reaction movements of the rolls have to be predictable too. This would include a complete simulation of the hole rolling aggregate in reaction with a material, which is impossible for complete mills
\end{abstract}

\section{Introduction and overview}

In the last 10 years a huge amount of systematic work was done and published on the effect thermomechanical processing during the ingot-to-billet conversion practice of alloy 718. [1-2] The role of minimum local strain for starting the recrystalisation, of the delta phase for pinning the achieved fine structure and of the strain rate sensitivity was evaluated on compression test flow curve analysis and its transformation to processing maps. [2-4] Once the main correlation of the forming parameters strain, strain rate and temperature where developed, numerical simulation added with microstructural models on deformation processes occur. [5-9] Following the mainly used forming technology, most of the development of predictive simulation on alloy 718 toke place on forging processes from cogging to closed die forging, although the idea of thermomechanical processing in rolling was well developed on steel, e.g. through the work of C. M. Sellars and J.J. Jonas. [6,7].

While in forging the FEM-method for part or full process simulation is very successful, in shape rolling the product dimensions, the product range and the variety of tools are far too much for a complete and economical FEM-solution. It is a powerful tool for a systematic evaluation of single steps, but the mechanics of a shaped roll gap is a very complex and not yet complete analytical described battlefield [10-17]. The main challenge in rolling calculation is the development of the shape during the single pass and the achievable technical relevant accuracy is very much dependent on the advanced user and the process data from experimental rolling. So 
due to the missing of a closed theory for rolling calculation for industrial purpose a simplified model based on experimental data for spread prediction was developed.

This model combined with technical monitoring of the relevant forming parameters leads to stable process prediction. The main parameter for microstructure control in 718 rolling is the temperature distribution over the cross section of the shape and the length of the trace. The validation of the calculation accuracy was made with systematic rolling trials in lab scales at the university TU-Bergakademie Freiberg and full-scale mill trials in Kapfenberg at Böhler Edelstahl GmbH.

\section{Metallurgical window of alloy 718}

The first step in defining the rough metallurgical window of alloy 718 is the calculation and or measurement of the delta solvus temperature (DST), governed by the main matrix elements Ni, $\mathrm{Cr}, \mathrm{Fe}$ and the main precipitation element niobium. Beside more accurate models a quick and conservative estimation leading to slightly lower temperatures is given under the following equation.

$$
\operatorname{DST}[K]=9.36 \times N i[\%]+18.40 \times \mathrm{Cr}[\%]+11.3 \times \mathrm{Fe}[\%]+48.78 \times N b[\%]
$$

For cogging temperatures above the delta solvus temperature $\left(\sim 1100{ }^{\circ} \mathrm{C}\right)$ was chosen, following the recommended theories [3]. The DST is the absolute maximum temperature the material should reach in the final forming steps for microstructural refinement. The minimum temperature is given through the freezing of the dynamic recrystalisation found in compression tests and extracted processing maps with $900^{\circ} \mathrm{C}$. The minimum strain can be estimated with large-scale compression tests under a few systematic temperature and strain rate variations, but always under the consideration of the initial used microstructure. In Fig.1 an etched cross section from compression test is combined with a FEM effective strain distribution chart at $980^{\circ} \mathrm{C}$. So the main parameters strain, strain rate and temperature can be found for the process window. The guiding parameter in processing alloy 718 is temperature control under fixed deformation regimes.

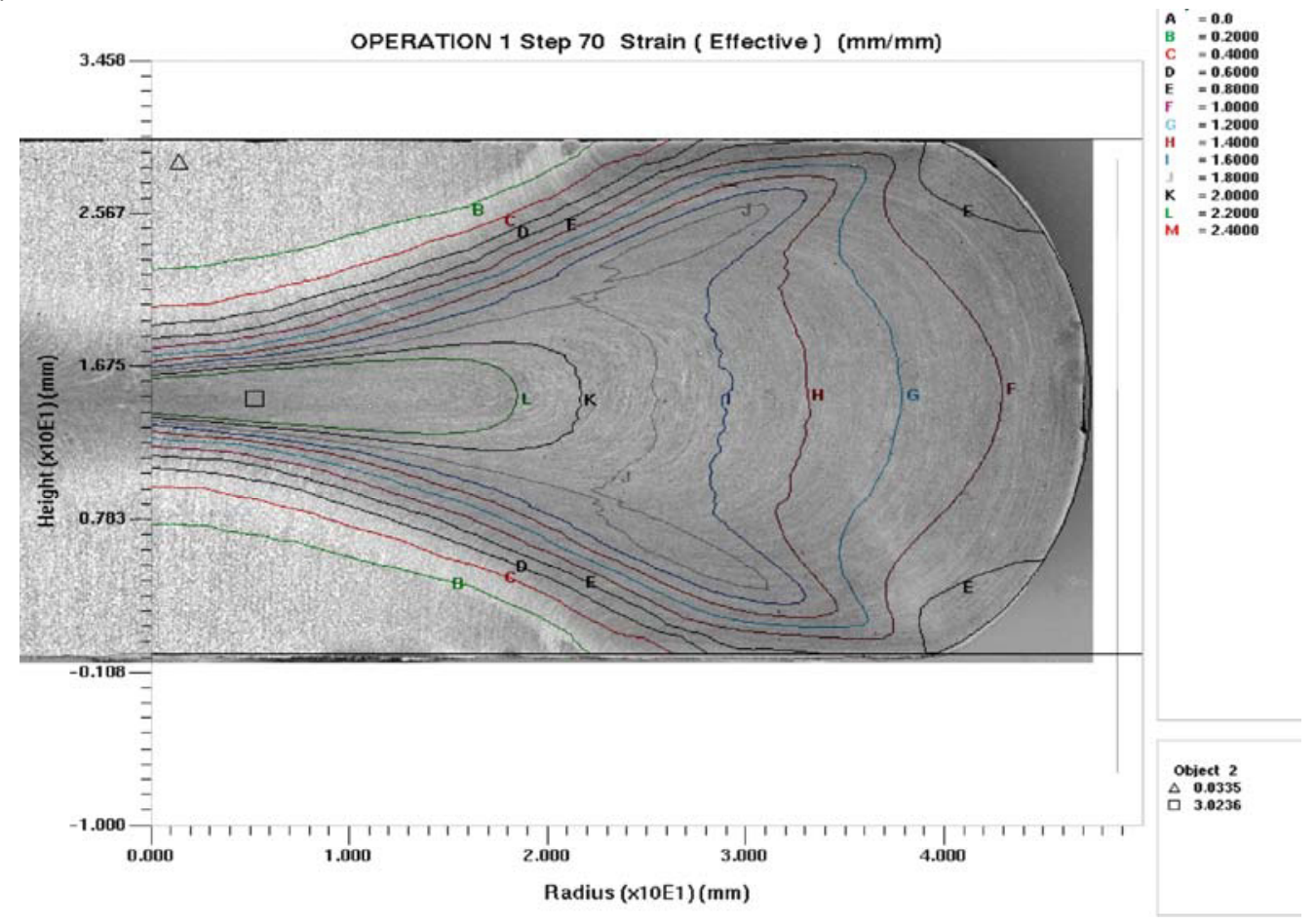

Figure 1. Strain effective over a cross section of a compression test sample at $980^{\circ} \mathrm{C}$ 


\section{Process window}

Beside the also in forging valid challenges of high deformation resistance and the needed tight temperature tolerances, rolling of nickel-based superalloys is extended complex trough the extremely enlarged length and surface of the product and the reduced possibilities for re heating. An advantage of rolling is the capability of higher deformation velocity.

Establishing a small temperature distribution over the whole cross-section, over the whole process is the main key to microstructural control. In Fig. 2 a systematic sketch is showing the effect of temperature distribution over a quarter cross-section and the process window. For case A) the hot start, only the surface region will hit the right window. A solution of the deltaphase, coarse grains and bad mechanical properties would be the result from the centre to the mid radius. Just lowering the temperature to case B) leads to drop out of the window at the surface. The structure would fit from the centre to the mid radius and would cause a not finished recrystalised (necklace) structure at the surface. The solution $\mathrm{C}$ ) combines a lower start and avoiding temperature losses plus the use of strain and strain rate to heat up the material again at the relevant regions.

This single aim is very much different to reach at the different stages of the used rolling technologies. In cogging of big ingots the free parameters to vary are strain (bites) and strain rate (velocity). But the huge rolling forces limit the possible strain. The strain rate is limited through the ingot length. The rolling direction has to be switched from bite to bite by using a reverse duo stand. So the maximum roll speed is limited. The free parameters for reverse rolling of bars in grooved rolls are strain rate and at a reduced level strain, because of the given groove shapes. For continuous rolling in grooved rolls there is only strain rate left, because of the tighter tolerances and the fixed calibrations of the rolls.

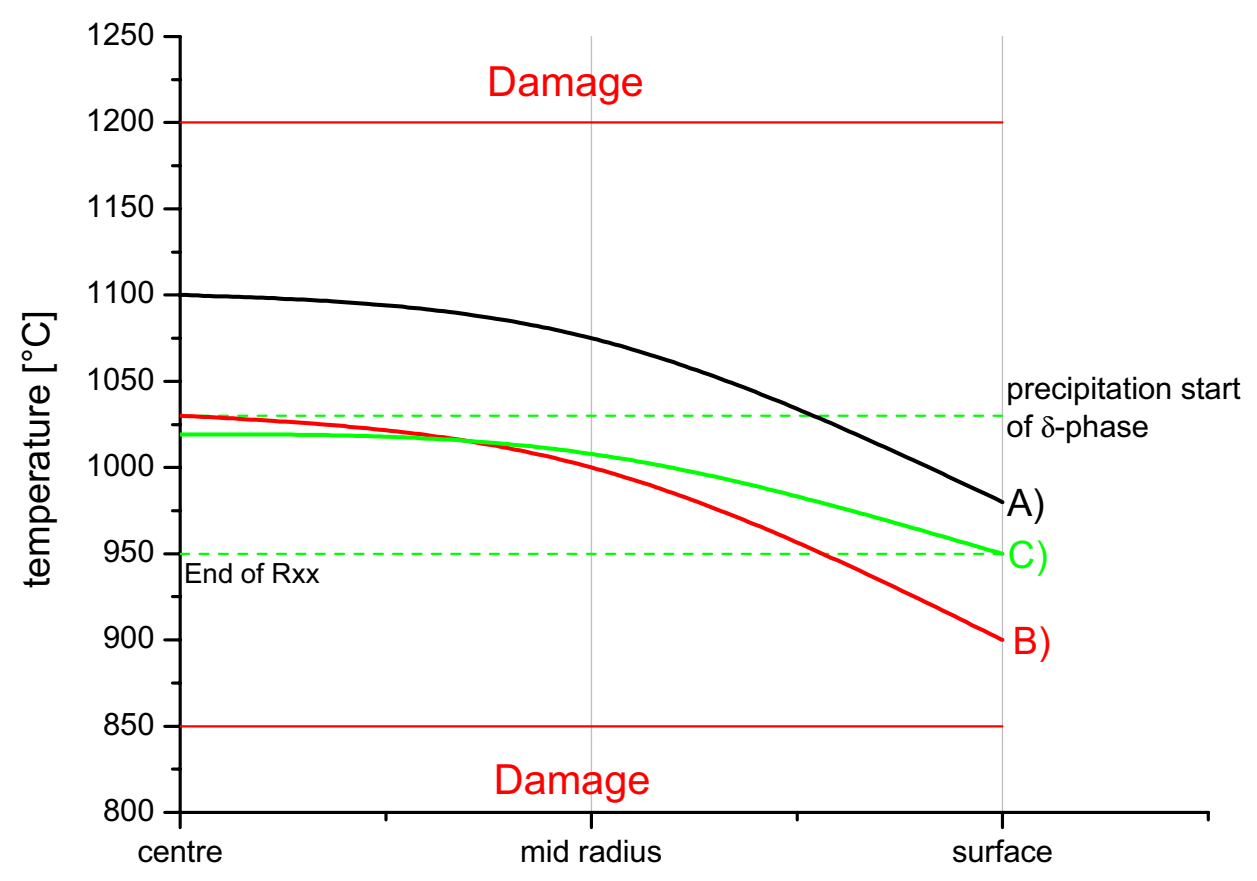

Figure 2. Schematic temperature distribution over cross section 

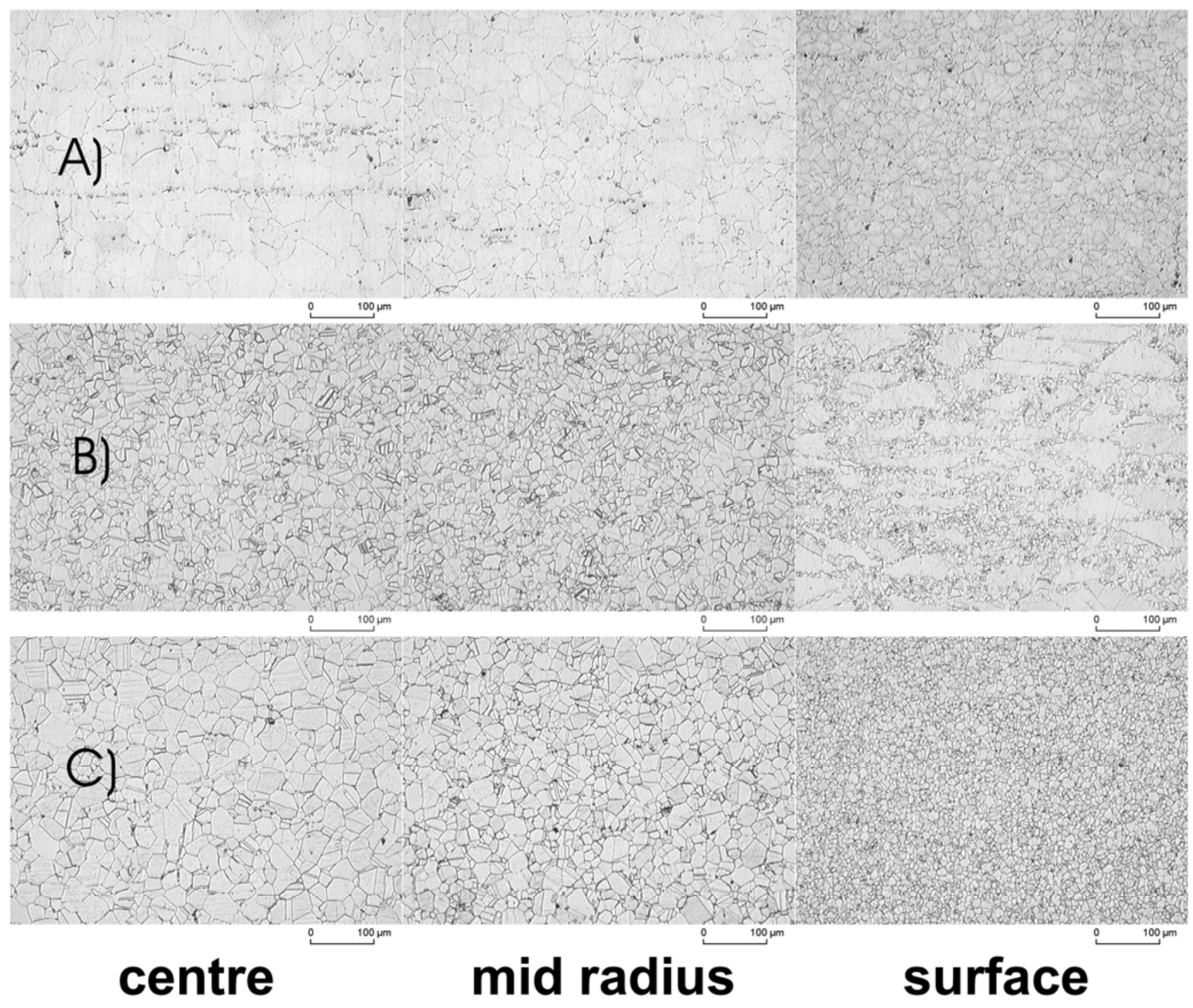

Figure 3. Microstructures following the temperature deviations

\section{Engineering tools}

\section{Modeling}

From the above mention demands to the process window a tool was needed to predict the temperature distribution over the cross section depended to the prior and the actual deformation. FEM-calculations can provide good information of physical properties over the cross section of a deformed shape. Systematic research on the influence of single parameters can be done. For engineering purpose much more global data are important like shape evolution and roll force. FEM-calculation of the rolling gap is easy to do under the assumption of stiff rolls with no roll deflection. But following the technical reality the reaction movement of rolls under big forces is a main key for save rolling prediction. To predict the roll deflection too, a simulation of the whole stand would be necessary. Due to the fact that FEM-modeling is very time consuming and also very much dependent from good processing data, the decision was made to create a simplified calculation model, which will be stabilized trough extended monitoring data out of the mills. To reach the main aim of a proper temperature distribution calculation, a good and conservative roll force calculation is needed. With the correct roll forces a safety assessment for the equipment and the energy input to the material is possible. The main challenge in rolling is 
the shape prediction in grooved rolls. [10-17] Once the correct shape evolution is known, an exact contact area and the following roll force are predictable. So the concentration was focused on an exact shape evolution calculation based on the knowledge of the final shape. This has to be known by measurement or through other spread calculation models, like the Freiberger Breitungsmodell [10] following the school of A. Hensel and T. Spittel [12].

The basic approach was taken from the stripe model of flat rolling extended through an analytical assessment of the local shape of every stripe plain in the grooved roll contact. The contact length is divided into several stripes. The cross section shape is divided in several columns. The single columns get their deformation trough the calculated shape evolution for every step. In every stripe plain a 2D-FDM-temperature calculation is performed and handed over to next stripe plain. For the calculation of continues rolling mills with more than 10 bites a further simplification was done. Ones the rolling schedule is geometrical developed the temperature calculation was reduced on an equivalent square-rectangular shape evolution, based on the cross section area of the oval-round evolution $[9,15]$. This simplifications lead to a quick and accurate enough temperature distribution and evolution over a complete rolling track. Even if single temperatures deviate to reality, it is a very quick tool to find out the main driving parameters to establish temperature uniformity over many passes. This calculation can be done in a few minutes compared to days and weeks with more advanced FEM-models.

Very important for the accuracy of the model are the monitoring data from the used equipment. Both shape and temperature evolution, as well as roll reaction parameters have to be monitored to achieve tight temperature tolerances.

\section{Validation}

For validation FEM-and FDM-modeling from experimental rolling was performed. (Table1) As mentioned above the roll force is a main indicator for the accuracy of any rolling model. So much attention was paid to this parameter in measurement and calculation. The roll forces, moments, temperatures and geometries where recorded. (Fig.4 and 5)

Table 1. Parameter of experimental flat rolling trials (roll diameter: $360 \mathrm{~mm}$ )

\begin{tabular}{|l|l|}
\hline Deformation & $10 ; 20 ; 30 ; 35 \%$ \\
\hline Velocity & 0,$5 ; 1 ; 1,3 \mathrm{~m} / \mathrm{s}$ \\
\hline Temperature & $850 ; 900 ; 950 ; 1000 ; 1050{ }^{\circ} \mathrm{C}$ \\
\hline
\end{tabular}
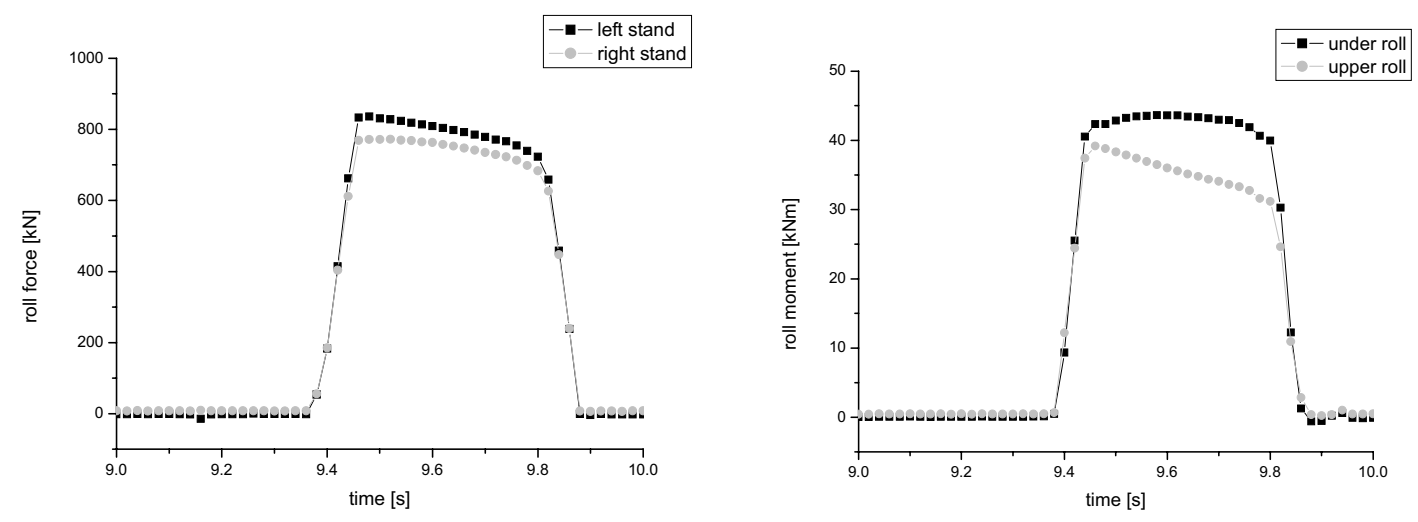

Figure 4. Roll force and roll moment data from lab scale flat rolling trial Roll velocity $1 \mathrm{~m} / \mathrm{s}$ with $20 \%$ Reduction 


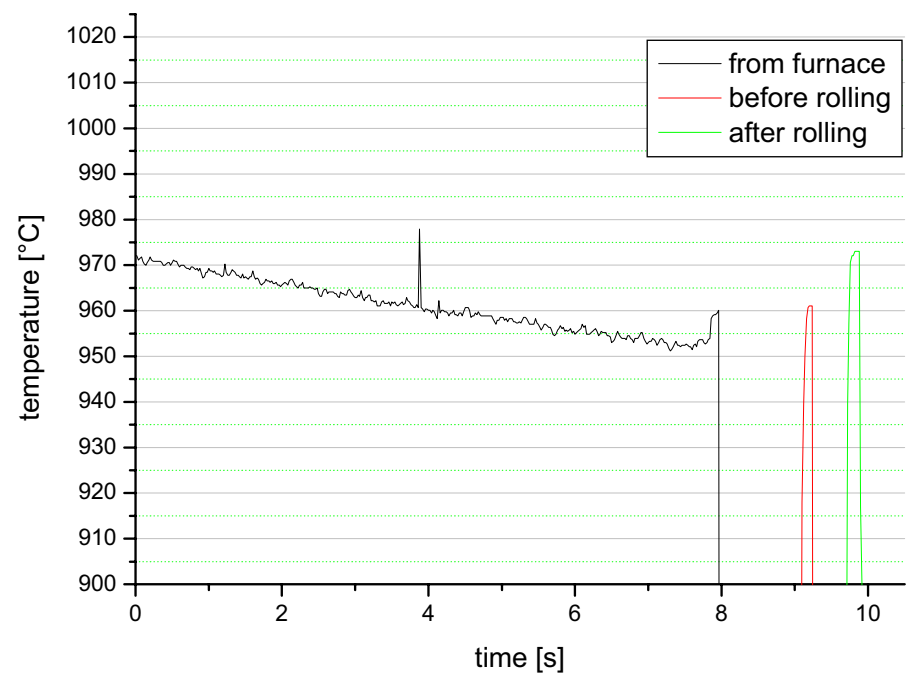

Figure 5. Experimental surface temperature of rolling trial

The predicted (Fig.6) forces are always higher by the new model compared to the measured and FEM calculated ones. One explanation is that the contact area is enlarged trough elastic roll flattening. This was not estimated for the FEM calculation, while the new model is based on the knowledge of the experimentally reached end shapes and that includes this information. In terms of technical risk assessment this result is acceptable as conservative, as long as the systematic behavior is predicted.

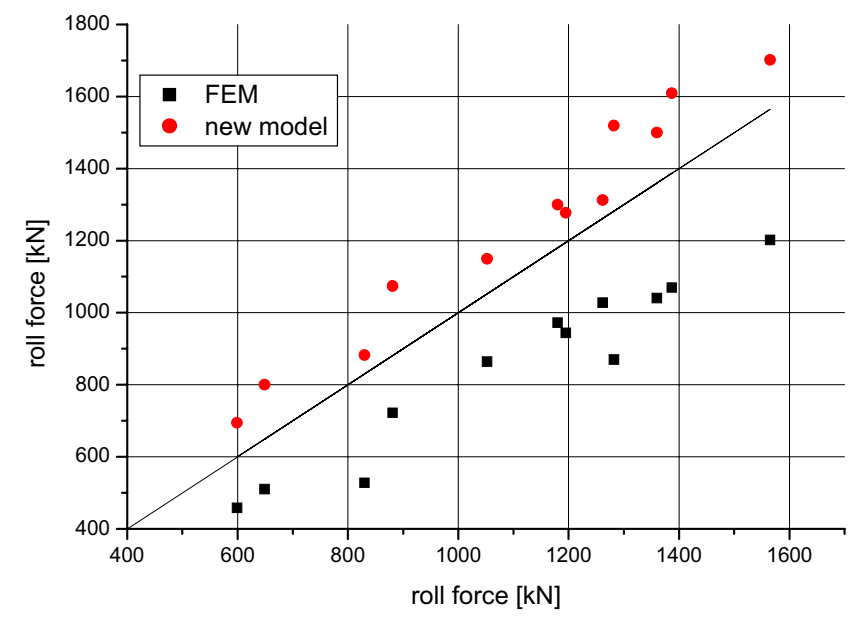

Figure 6. Roll forces from experimental rolling compared with calculated values

\section{Microstructure Evaluation}

The microstructural assessment of measured rolling trials is actually in progress to evaluate several microstructural calculation models [8,9] for alloy 718. The alloy 718 microstructural evolution is very predictable once the right temperature window was hit. A question of accuracy is the evaluation of the near surface region where in rolling strong temperature gradients can occur as a result of roll contact and water-cooling. These regions are very small with a few millimeters, but relevant due to the fact that in rolling much tighter tolerances with lower machining extra are used. These areas have to be evaluated through systematically and periodically repeated microstructural assessment. A specific preparation and etching method was found to evaluate the recrystalised fraction with image analysis. This special etching clearly 
indicates the not recrystalised grains down to a few percent with the advantage of a big observation area compared to equivalent techniques like EBSD.
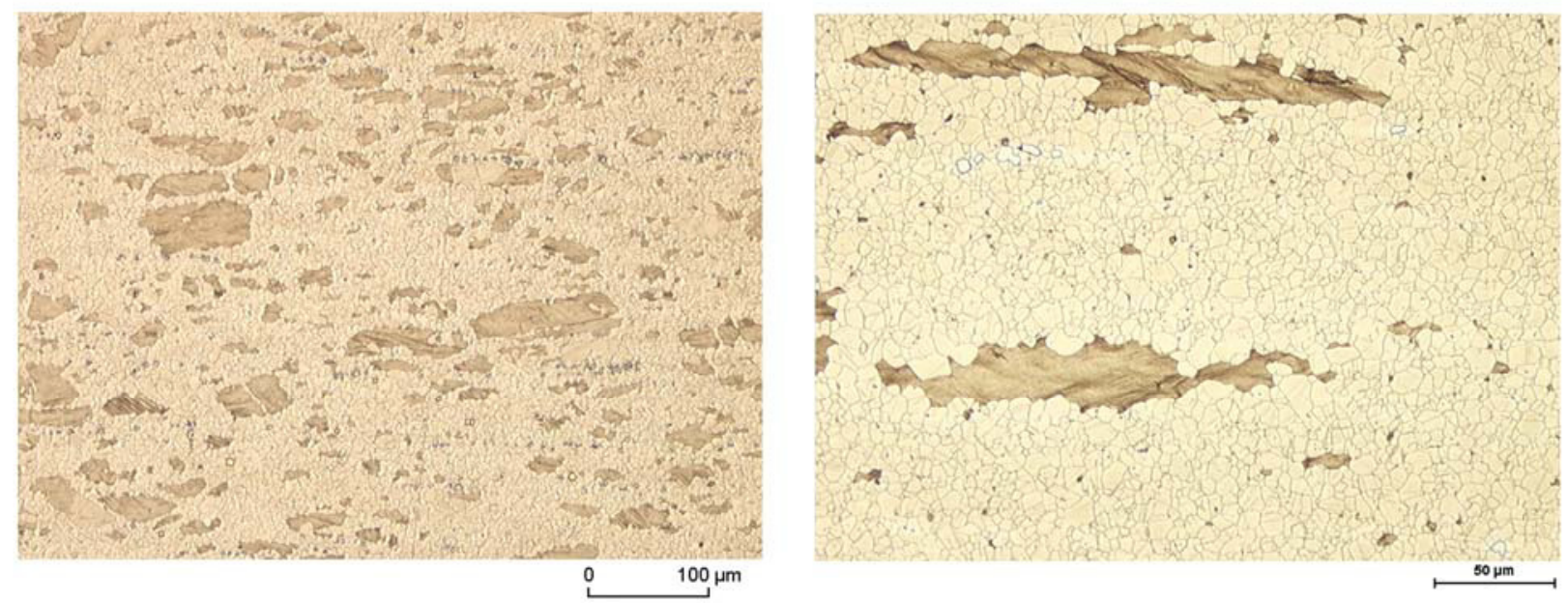

Figure 7. Fraction of not recrystalised grains on etched samples

In the following chapters a few examples are sketched for applied large scale rolling techniques from ingot cogging to precision shape rolling.

\section{Cogging of 20 inch ingots}

The cogging of ingots in a reverse duo roll stand is state of the art for many steel grades up to powder metallurgical tool steel. The main question due to cogging of alloy 718 ingots is the maximum applicable roll force and the minimum temperature achievable at the end of the rolling sequence. So a calculation of a proposed rolling schedule for a 16 inch VAR ingot showed roll forces up to 1000 tones, which can be applied to a stand with $5400 \mathrm{~kW}$ power capacity. The temperature development can be manipulated through a certain combination of bite sequences to heat the billet via rolling, trough the applied deformation energy. The online monitoring of roll forces, velocities and work piece temperatures ensure a stabile repeatability of the developed process. (Fig. 9)

The advantage of rolling is the higher deformation velocity and shorter dead times between the hits compared to forging press operation. Very much attention has to be paid on the balance between the input of deformation and the stable movement in the grooves. Because, compared to forging, there is no possibility for manipulation of the ingot during the bite. The ingot has to move stable through the rolls without pass outs.

With the development of this heating via rolling the ability of longer rolling sequences of one piece with more weight was given. Again the maximum roll forces has to be calculated to ensure a save processing of the 20 inch ingot. With forces up to 1200 tones the stand is able to do this job in an economical manner. The 20-inch ingot now can be transferred into a 10-11 inch billet in one heat in a few minutes. (Fig. 10) 


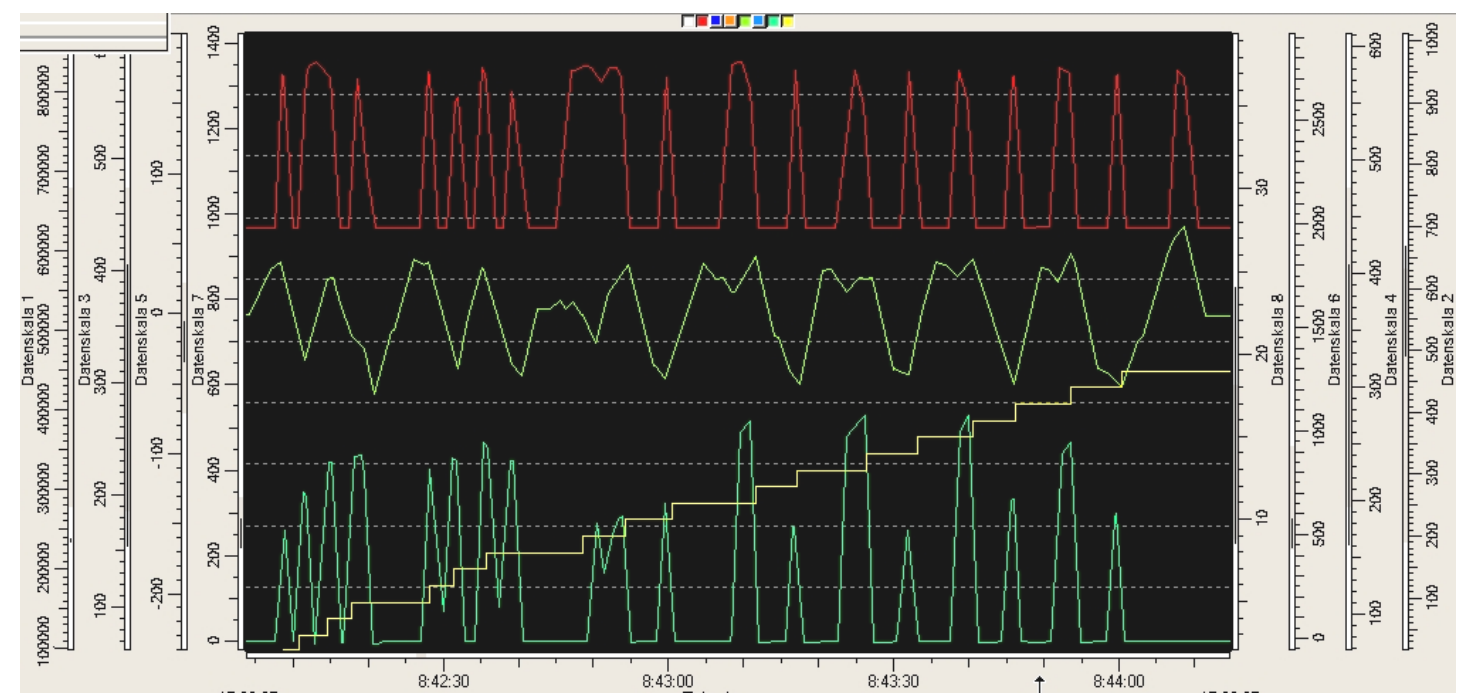

Figure 9. Process monitoring of ingot break down, Parameters from above: temperature, roll velocity, bite, force

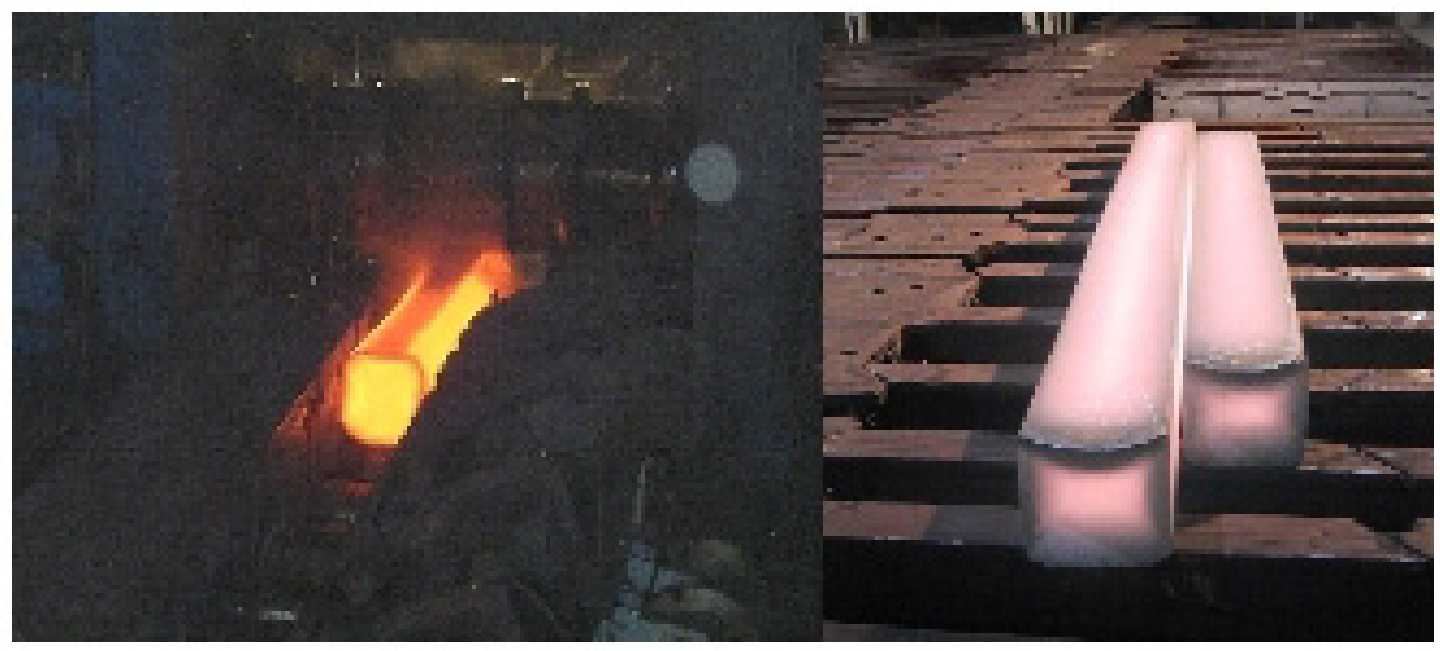

Figure 10. Rolling of $510 \mathrm{~mm} / 20$ inch ingot in the cogging mill to pre-billet $250 \mathrm{~mm} / 10 \mathrm{inch}$

\section{Reverse rolling to bar}

Starting with the pre rolled billet the second heat has to ensure the microstructural refinement over the whole cross section of the bar product. A reduction from $\sim 70.000 \mathrm{~mm}^{2}$ (square $250-280$ $\mathrm{mm}$ ) to e.g. $7800 \mathrm{~mm}^{2}$ (round $100 \mathrm{~mm}$ ) has to be established in one heat without re-heating possibilities. The rolling sequence was divided into two temperature steps. Starting with a temperature above DST, a pre forming of the billet is followed by a final forming under DST. This is realized trough a temperature drop between two stands. The main challenge is that the drop is equal for the centre and the surface within the limits shown in Fig.3 curve c). This only possible trough a rolling sequence with local deformation concentration in the surface region of the cross section under controlled velocities, paying attention not to overheat the centre of the bar again. In Fig. 11 a monitoring data set from the last two passes, a square-oval and an oval-round pass is shown combined with calculated temperature distribution over the cross section of these passes. With roll forces between 300 and 700 tones in square- oval passes roll deflections from 2-6 mm can occur. These roll deflection has to be put into account for safe schedule design. With this technique a temperature gradient of maximum $50 \mathrm{~K}$ over the cross section can be achieved. 

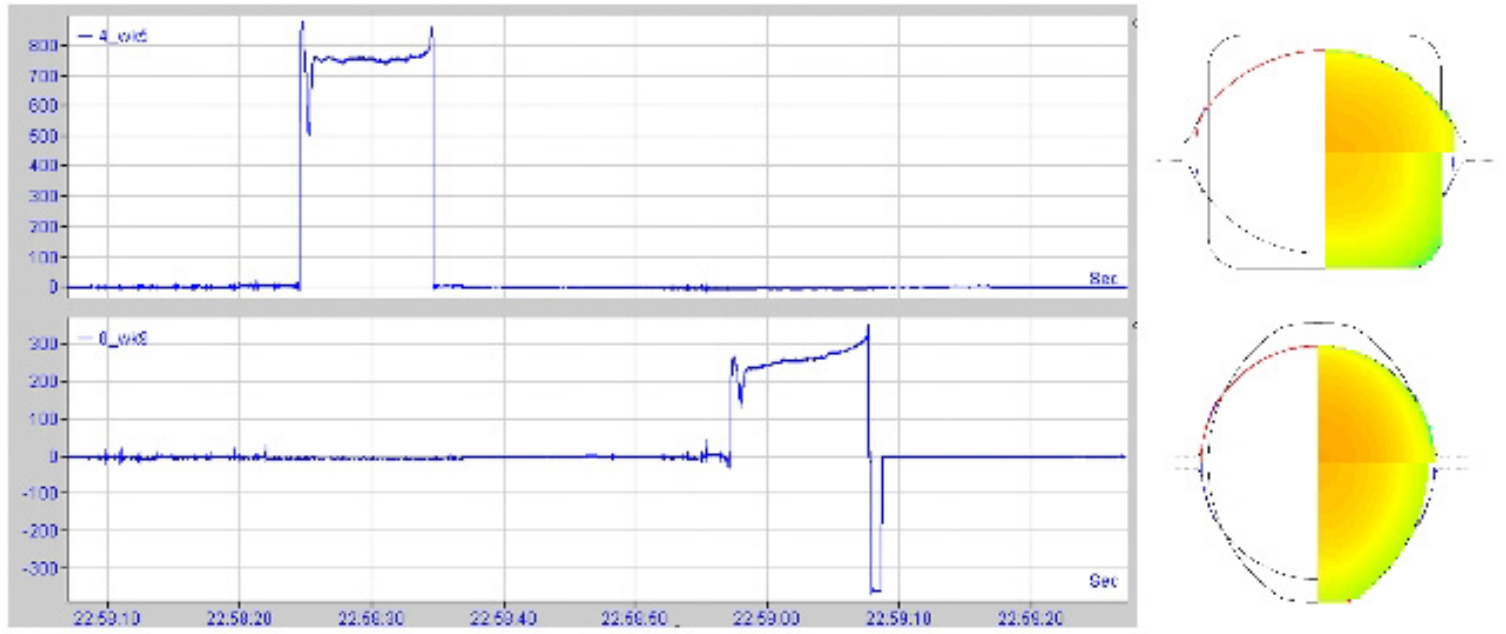

Figure 11. Process monitoring of shape rolling operations and calculated temperature distribution

\section{Continues rolling to bar}

Continuous rolling for bar products with thigh tolerances leaves not many possibilities in varying the deformation per pass. Only the roll velocity is a free parameter for temperature control. Due to the fact that in continues rolling the final diameters lead to the number of used rolls, every diameter has to have his own velocity program.

For alloy 718 precision bar products a three heat rolling sequence leads to very fine microstructures with extended mechanical properties. A pure under DST rolling sequences is established as a third heat, following the before described first heat cogging and second heat TMP rolling to billet.

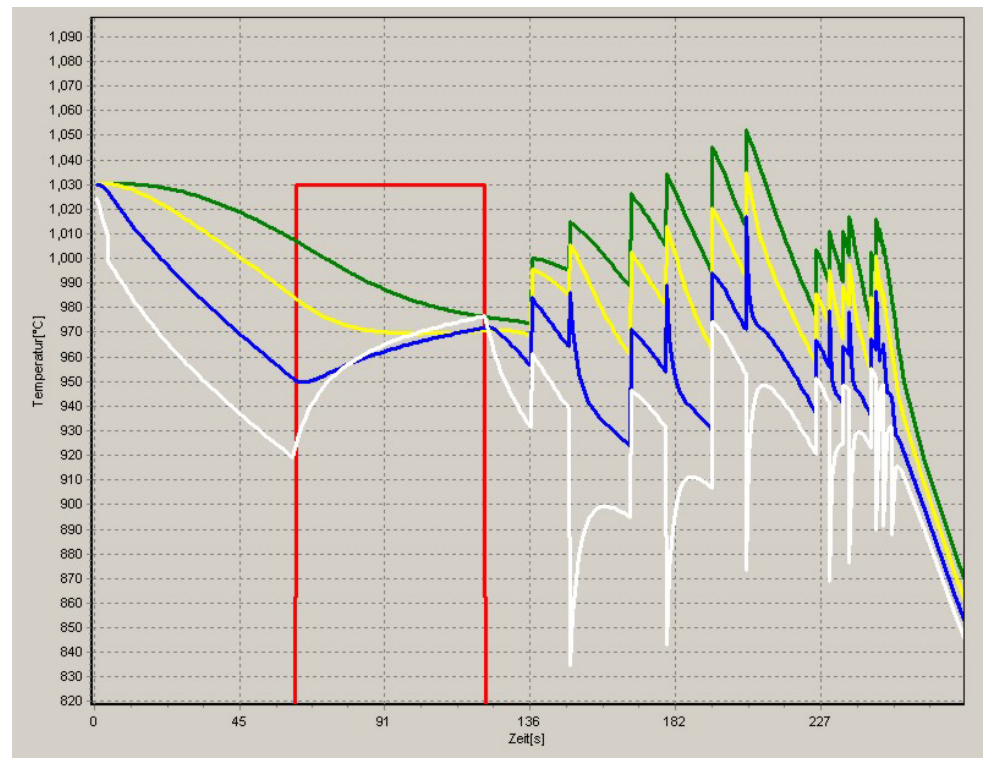

Figure 12. Temperature development and distribution for a continuous rolling sequence

With this rolling technique a very fine microstructure of average ASTM No. 12 (Fig.13, 14) can be achieved. The sense full use of TMP practice in alloy 718 rolling can be seen at the mechanical properties (Table 3) achieved with lower alloying element level then usually used. (Table 2) 


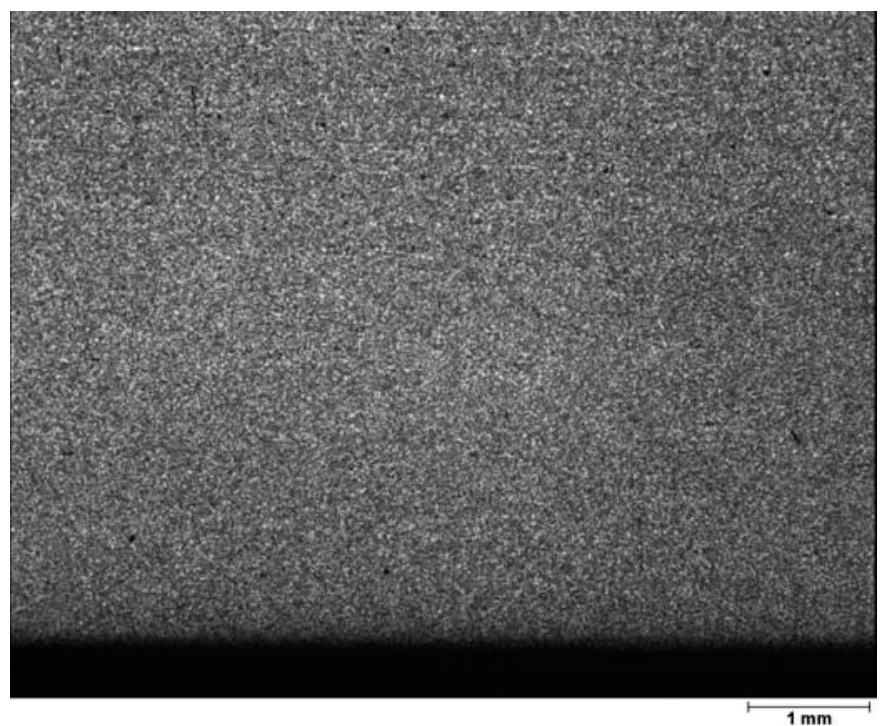

Figure 13. Longitudinal surface section of precision flat bar

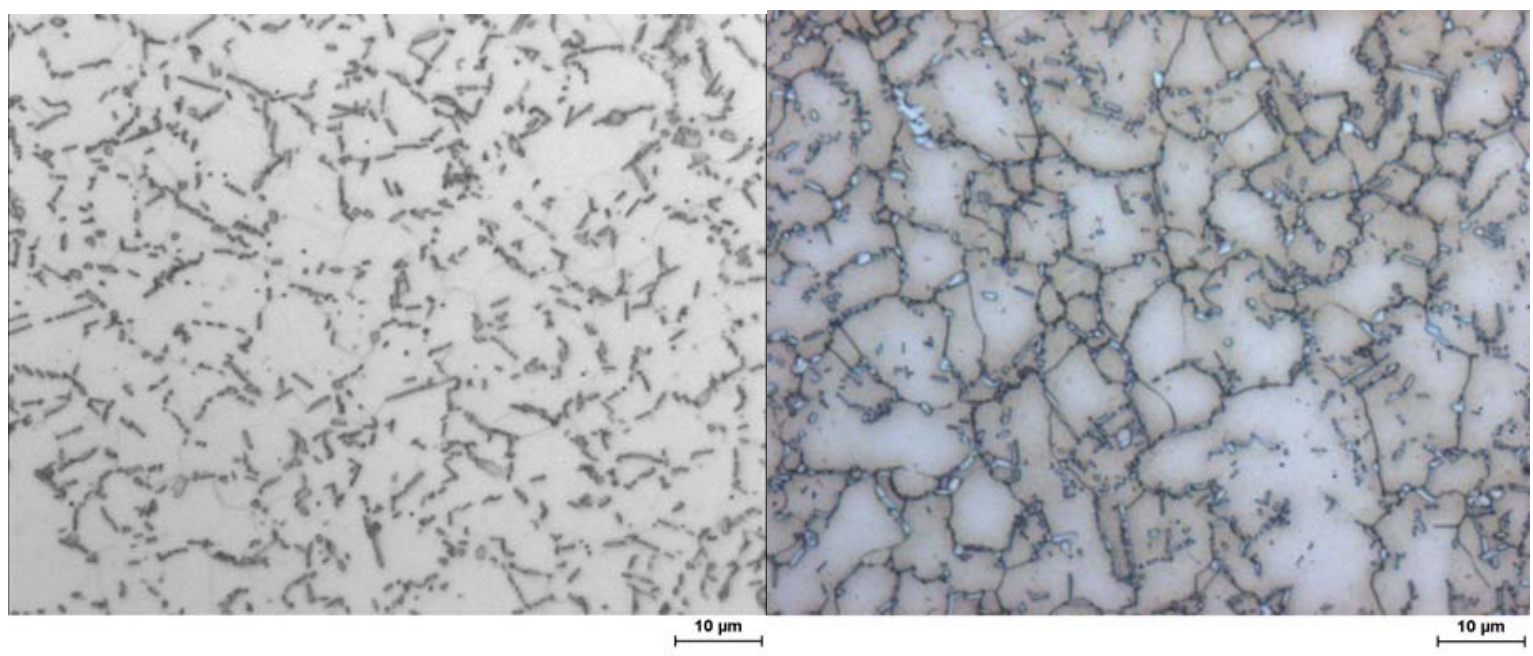

Figure 14. Microstructure of precision rolled flat bar 50x12,5 mm Left picture: delta phase distribution Right picture: grain size distribution

Table 2. Chemical analysis alloy 718 rolled to precision rolled flat bar 50x12,5 mm

\begin{tabular}{|c|c|c|c|c|c|c|c|c|c|}
\hline & $\mathbf{C}$ & $\mathbf{A l}$ & $\mathbf{C r}$ & $\mathbf{M o}$ & $\mathbf{N i}$ & $\mathbf{N b}+\mathbf{T a}$ & $\mathbf{T i}$ & $\mathbf{F e}$ & $\mathbf{M g}$ \\
\hline Min & 0.02 & 0.4 & 17 & 2.8 & 50 & 5.15 & 0.65 & & 0 \\
\hline Act. & 0.023 & 0.54 & 17.76 & 3.01 & 54.06 & 5.17 & 0.98 & 18.29 & 0.0019 \\
\hline Max & 0.04 & 0.8 & 21 & 3.3 & 55 & 5.5 & 1.15 & 19 & 0.003 \\
\hline
\end{tabular}

Table 3. Tensile properties of precision rolled flat bar 50x12,5 mm

\begin{tabular}{|c|c|c|c|c|}
\hline & UTS & YS & A5 & $\mathbf{Z}$ \\
\hline & $\mathrm{MPa}$ & $\mathrm{MPa}$ & $\%$ & $\%$ \\
\hline room temp. & $\mathbf{1 2 7 6}$ & $\mathbf{1 0 3 4}$ & $\mathbf{1 2}$ & $\mathbf{1 5}$ \\
\hline & 1502 & 1286 & 17 & 39 \\
\hline & 1493 & 1265 & 20 & 48 \\
\hline & 1535 & 1353 & 18 & 45 \\
\hline $\mathbf{6 5 0 ^ { \circ } \mathbf { C }}$ & $\mathbf{1 0 0 0}$ & $\mathbf{8 6 2}$ & $\mathbf{1 2}$ & $\mathbf{1 5}$ \\
\hline & 1210 & 1062 & 23.7 & 64.8 \\
\hline & 1212 & 1044 & 26.3 & 65 \\
\hline & 1188 & 1055 & 26 & 62.3 \\
\hline
\end{tabular}




\section{Conclusions}

The capability of TMP processing of alloy 718 was shown in a broad overview over several rolling techniques. Basic knowledge of the thermomechanical needs of the alloy combined with use full engineering tools can lead to a proper product design with very competitive properties on economical forming technologies. Monitoring data of deformation steps are important tools to tighter process control and product stability and establish possibilities for using of simplified prediction models. Lab scale rolling was used to validate the new developed rolling model with additional evaluation of the achieved microstructures to use these data for microstructural prediction in the future. The roll force was found to be global reaction parameter of the process indicating the accuracy of the rolling calculation to predict temperature distribution over shape cross section. The temperature control is the main key to control the microstructural evolution of alloy 718. Further investigation will be made to improve the developed tools on the field of shape prediction.

\section{References}

1 C.I. Garcia, D.E. Camus, E.A. Loria, A.J. DeArdo, "Microstructural Refinement of ascast Alloy 718 via thermomechanical processing", Proceedings of the International Symposium on Superalloys 718, 625 and Various Derivates, E.A. Loria, ed .,TMS 1991, pp. 925-941.

2 C.I. Garcia, G.D. Wang, D.E. Camus, E.A. Loria, A.J. DeArdo, "Hot Deformation Behavior of superalloy 718", Proceedings of the International Symposium on Superalloys 718, 625 and Various Derivates, E.A. Loria, ed .,TMS 1994, pp. 293-302.

3 N. Srinivasan, Y.V.R.K. Prasad, "Microstructural Control in Hot Working of In-718 Superalloy Using Processing Map”, Metallurgical and Materials Transaction A, 25 (1994), 2275-2284.

4 Y.V.R.K. Prasad, S. Sasidhara, Hot working guide, vol.1 (Metals Park, OH: American Society for Metals, 1997)

5 R.A. Jaramillo, F.S. Suarez, J.A. Plyburn, D.E. Camus, "Evaluation of an Inconel Alloy 718 Microstructural Evolution Model”, Proceedings of the International Symposium on Superalloys 718, 625 and Various Derivates, E.A. Loria, ed .,TMS 1997, pp. 257-266.

6 C.M. Sellars, "Hot working and forming processes, e.d. C.M. Sellars and G.J. Davies, Met.Soc., London, (1980)

7 A. Laasroui, J.J. Jonas, "Prediction of Temperature Distribution, Flow Stress and Microstructure during Multipass Hot rolling of Steel Plate and Strip", ISIJ, Vol. 13,(1991), no. 1, pp. 95-105.

8 M. Stockinger, "Mikrostrukturelle Simulation des Gesenkschmiedens von Nickelbasislegierungen“ (Dissertation, TU-Graz, 2003)

9 C. Sommitsch, "Theorie und Modell der mikrostrukturellen Entwicklung von NickelBasis-Legierungen während dem Warmwalzen“ (Dissertation, TU-Graz, 1999).

10 B. Schmid, "Entwicklung und Erprobung einer Softwarelösung für die mathematische Simulation des Walzens von Langprodukten", Freiberger Forschungshefte, B 282, 1997

11 G. Goldhahn, "Formänderungsverteilung sowie Kraft- und Arbeitsbedarf beim Walzen in der Streckkaliberreihe Rund-Oval“, (Diss., Bergakademie Freiberg, 1982)

12 A. Hensel, T. Spittel, "Kraft- und Arbeitsbedarf bildsamer Formgebungsverfahren“, VEB Deutscher Verlag für Grundstoffindustrie Leipzig, 1980

13 G. Zouhar, "Umformkräfte beim Walzen in Streckkalibern", Freiberger Forschungshefte, B 52

14 Z. Wusatowski, "Fundamentals of rolling", Pergamon Press, London, 1969 
15 Y. Lee, H.J. Kim, S.M. Hwang, "Analytic model for the prediction of mean effective strain in rod rolling process”, Journal of Materials Processing Technology 114, (2001), pp.129-138.

16 H.J. Kim, T.H. Kim, S.M. Hwang, “ A new free surface scheme for analysis of plastic deformation in shape rolling”, Journal of Materials Processing Technology 104, (2000), pp.81-93.

17 Y. Lee, S. Choi, Y.H. Kim, "Mathematical modell and experimental validation of surface profile of a work piece in round-oval-round pass sequence”, Journal of Materials Processing Technology 108, (2000), pp.87-89. 